\title{
Altered White Matter Diffusivity of the Cingulum Angular Bundle in Posttraumatic Stress Disorder
}

\author{
Christopher L. Averill ${ }^{a, b}$ Lynnette A. Averilla, b Kristen M. Wrocklage ${ }^{a-c}$ \\ J. Cobb Scott ${ }^{d, e}$ Teddy J. Akiki ${ }^{a, b}$ Brian Schweinsburg ${ }^{a, b}$ \\ Steven M. Southwick ${ }^{a, b}$ John H. Krystal ${ }^{a, b}$ Chadi G. Abdallah ${ }^{a, b}$ \\ ${ }^{a}$ National Center for PTSD, Clinical Neurosciences Division, US Department of Veterans Affairs, West Haven, CT, USA; \\ ${ }^{b}$ Department of Psychiatry, Yale University School of Medicine, New Haven, CT, USA; ' Gaylord Specialty Healthcare, \\ Department of Psychology, Wallingford, CT, USA; ${ }^{d}$ Department of Psychiatry, Perelman School of Medicine, \\ University of Pennsylvania, Philadelphia, PA, USA; ${ }^{e}$ VISN4 Mental Illness Research, Education, and Clinical Center, \\ Philadelphia VA Medical Center, Philadelphia, PA, USA
}

\section{Keywords}

Posttraumatic stress disorder - Cingulum - Cingulate .

White matter tractography · Fractional anisotropy - TRActs

Constrained by UnderLying Anatomy · Neuroimaging ·

Veteran · Diffusion magnetic resonance imaging · Diffusion tensor imaging

\begin{abstract}
Purpose of the Study: Prior studies showed posttraumatic stress disorder (PTSD)-related alterations in white matter integrity, but most of these studies have used region-based approaches. We address this limitation by investigating the relationship between PTSD severity and fractional anisotropy (FA) using a tract-based approach. Procedures: Structural and diffusion magnetic resonance imaging were acquired from 67 combat-exposed US Veterans and processed using FSL/FreeSurfer TRActs Constrained by UnderLying Anatomy. Partial correlations were conducted between PTSD severity
\end{abstract}

and FA of the cingulum and uncinate fasciculi covarying for age, sex, and head motion. Results: Only FA of the left cingulum angular bundle (CAB) was positively correlated with PTSD symptom severity $(r=0.433, p=0.001, d f=57)$ and remained significant after Bonferroni correction. Conclusions: This finding may imply greater organization of the $C A B$ with increasing PTSD severity. The CAB connects directly to the cingulate cortex and the hippocampal subiculum, critical nodes of the default mode network, as well as being implicated in neurodegeneration pathology, decision-making, and executive functions, which may help explain previously shown alterations in this network in PTSD. Message of the Paper: Further study of white matter tract integrity in PTSD is warranted, particularly to investigate whether the $C A B$ connections with both higher-order cognitive functioning and emotion processing regions contribute to the pathophysiology and comorbidity of PTSD.

(c) 2018 S. Karger AG, Basel

\section{KARGER}

(c) 2018 S. Karger AG, Basel 


\section{Introduction}

Despite decades of psychiatric research, a comprehensive understanding of the network disruptions [1] predisposing and underlying posttraumatic stress disorder (PTSD) is still emerging $[2,3]$. While the majority of neuroimaging investigations have focused on structural [4] and functional [5] aspects of PTSD, there is a growing body of literature regarding white matter integrity related to the disorder. Using diffusion-weighted magnetic resonance imaging (dMRI), researchers can use methods such as diffusion tensor imaging (DTI) and fiber tractography to estimate the density and directionality of neural and membrane integrity, using the proxy measures of fractional anisotropy (FA) and mean diffusivity [6-8].

Although other regions of interest (ROI) have been implicated, analyses using DTI and tractography have most consistently demonstrated microstructural alterations of the cingulum and the uncinate fasciculus (UNC) in PTSD [9-19]. However, there have been inconsistencies in the literature in the directionality and extent of alterations. These inconsistencies are highlighted by a meta-analysis of DTI studies in PTSD, which identified clusters of both increased and decreased FA in the bilateral cingulum [20]. Among other reasons, it is possible that these inconsistencies may be due to methodological differences and limitations. Prior literature has focused primarily on region-based, rather than tract-based, FA assessment. In this study, we attempted to address this potential gap in the literature by examining the relationship between PTSD severity and cingulum/UNC FA in combat-exposed US Veterans, using a tract-based approach termed TRActs Constrained by UnderLying Anatomy (TRACULA) [21].

The cingulum and UNC are fiber bundles of the fronto-limbic circuit. The cingulum hugs the corpus callosum and is predominantly comprised of short fibers that connect the cingulate cortex, and nearby regions of the frontal, parietal, occipital, and temporal lobes [22]. Of particular relevance to PTSD, the cingulum connects the cingulate cortex and the hippocampus [15], 2 regions implicated in the pathophysiology of PTSD [23-26], which, if impaired, may delay or prevent recovery after exposure to trauma due to their respective roles in learning, memory, and fear processing [27]. The UNC connects portions of the temporal lobe with the inferior frontal gyrus [18]. This connection facilitates communication between the amygdala and the medial prefrontal cortex, a relationship that is critical for appropriate fear expression and threat response [28].
To address the limitations of deterministic, local tractography, including seed and target selection, and to facilitate comparison of voxel-wise data across subjects and populations, Yendiki et al. [21] developed TRACULA, a probabilistic, global method to automate reconstruction of white matter pathways while incorporating information from anatomical priors. This method may yield more robust, clinically relevant biomarkers of PTSD severity because it is standardized, automated, and constrained by underlying anatomy [21]. Based on prior studies, we predicted that PTSD symptom severity would be correlated with FA of the cingulum and uncinate tracts. In addition, to inform future studies, we conducted a number of exploratory analyses investigating other white matter tracts, as well as differences in these tracts by group (i.e., PTSD vs. combat control [CC]).

\section{Methods}

\section{Participants}

Sixty-seven US Veterans consented into a study approved by the Institutional Review Boards of the Yale School of Medicine and the VA Connecticut Healthcare System. All 67 participants were combat-exposed, of which 33 PTSD subjects and 34 CCs were well matched in terms of age, sex, and IQ. This group of participants has been discussed in prior publications from our group, in which we reported on PTSD associations with: gray matter integrity [29, 30], volumetric alterations [31], and functional dysconnectivity [32]. In this manuscript, we present the first DTI results from this cohort. Eligibility was specific to the parent study, which excluded psychotic, bipolar, learning, attentional, and major neurological disorders; moderate or severe traumatic brain injury; MRI safety concerns; and use of benzodiazepines. To improve generalizability, comorbidities common to PTSD were permitted in the study, such as depression, anxiety, substance and alcohol disorders, and stable antidepressant use.

\section{Clinical Measurement}

The Clinician Administered PTSD Scale for the DSM-IV (CAPS) [33] was used to ascertain PTSD diagnosis and symptom severity, and psychiatric comorbidities were assessed using the Structured Clinical Interview for the DSM-IV [34]. The Combat Exposure Scale [35] and the Wechsler Test of Adult Reading [36] were used to estimate trauma exposure and premorbid IQ respectively.

\section{Neuroimaging Acquisition and Processing}

All subjects completed structural MRI (sMRI) and dMRI MRI, which were acquired in a Siemens TIM Trio 3 Tesla magnet with a 32-channel head coil. Structural MRI included 2 T1weighted MPRAGE scans $(\mathrm{TR}=2,530 \mathrm{~ms}$; TE $=2.71 \mathrm{~ms}$; $\mathrm{TI}=1,200$ ms; Flip $=7^{\circ}$; Voxel $\left.=1.0 \times 1.0 \times 1.0 \mathrm{~mm}\right)$ and dMRI were acquired with diffusion weighting $\left(b=1,000 \mathrm{~s} / \mathrm{mm}^{2}\right)$ along $128 \mathrm{vec}-$ tors $\left(\mathrm{TR}=7,400 \mathrm{~ms} ; \mathrm{TE}=115 \mathrm{~ms} ;\right.$ Flip $=90^{\circ} ;$ Voxel $=1.7 \times 1.7 \times$ $3.0 \mathrm{~mm}$ ). The first image was acquired without diffusion weighting
Averill et al. 


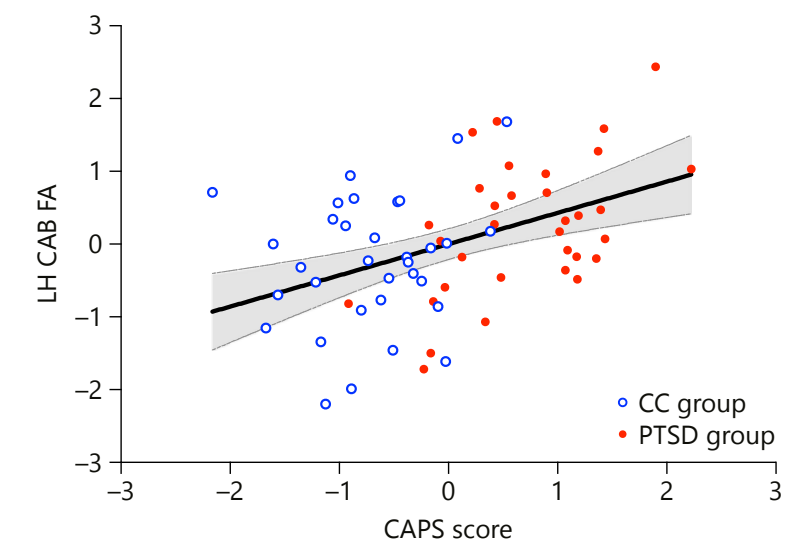

Fig. 1. PTSD Severity is Associated with Fractional Anisotropy (FA) in the Left Cingulum Angular Bundle (CAB). Plotted CAPS score and FA values are residuals after controlling for age, sex, antidepressant status, and motion.

$\left(b=0 \mathrm{~s} / \mathrm{mm}^{2}\right)$. Consistent with prior literature [21, 32, 37, 38], and described in greater detail in the online supplementary Materials (for all online suppl. material, see www.karger.com/ doi/10.1159/000490464), DTI processing was conducted using FMRIB Software Library (FSL; https://fsl.fmrib.ox.ac.uk/fsl/fslwiki) [39], and TRACULA (FreeSurfer; https://surfer.nmr.mgh.harvard.edu) [40].

Statistical Analysis

Online supplementary Table S1 provides a summary of personal and clinical characteristics as well as dMRI head motion variables for comparison of PTSD and CC participants. CAPS score, age, sex, head motion, and all white matter data were evaluated for normality and were log-transformed if the variable was highly skewed or kurtosed. We conducted 2-tailed partial correlation analyses (1) to probe for associations between PTSD symptom severity and FA of the cingulum angular bundle (CAB), cingulum cingulate gyrus endings, and UNC; (2) to explore the other TRACULA-defined fasciculi; and (3) to inform on possible methodological differences with tensor-based ROI similar to those used in past literature. Analyses are further described in the supplement.

\section{Results}

\section{PTSD Severity and FA in Probabilistic}

Tracts (TRACULA)

FA of the left $C A B$ was positively correlated with PTSD symptom severity for the full group $(r=0.433, p=$ $0.001, d f=57)$ and the PTSD group $(r=0.534, p=0.005$, $d f=57$; Fig. 1) but was not correlated with severity in the CC group ( $p=0.492)$. Significant correlations remained after adjusting the alpha threshold for multiple comparison using Bonferroni (corrected alpha $=0.008$; 6 com- parisons). There were no associations between PTSD severity and the right $\mathrm{CAB}$, or with the cingulate gyrus endings or UNC in either hemisphere (Table 1). There was no significant association between PTSD severity and any other probabilistic white matter tract (Table 2). See online supplementary Table S2 for results of a multivariate GLM comparing FA in all tracts between PTSD and CC groups.

\section{PTSD Severity and FA in Tensor-Based ROI}

In this full-group analysis, FA in the left corticospinal tract was negatively correlated with PTSD symptom severity $(r=-0.266, p=0.040, d f=58)$. However, this correlation failed to retain significance after adjusting the alpha threshold for multiple comparison using Bonferroni (corrected alpha $=0.0008 ; 62$ comparisons). There were no correlations between PTSD severity and any other ROI (see Table 3 for all correlations). Several trend-level associations were noted prior to Bonferroni correction: a negative trend with the splenium of the corpus callosum $(r=-0.232, p=0.074, d f=58)$, a negative trend with bilateral corticospinal tract $(r=-0.239$, $p=0.065, d f=58)$, a positive trend with the right IFO $(r=0.231, p=0.076, d f=58)$, and a positive trend with the bilateral ( $\mathrm{L}+\mathrm{R}$ composite) IFO $(r=0.241, p=0.063$, $d f=58)$.

\section{Discussion}

The results of this study partially confirmed our hypotheses. More specifically, we found that PTSD symptom severity was associated with integrity of the left $\mathrm{CAB}$, although we did not find significant associations between PTSD symptoms and other cingulum tracts or the UNC. The CAB is connected with brain regions underlying both higher-order cognitive functioning and emotion processing and implicated in neurodegeneration pathology [41]. Moreover, associations have been reported between $\mathrm{CAB}$ integrity and functioning in episodic memory, decision-making, and executive control $[42,43]$. The CAB has also been shown to directly connect the posterior cingulate cortex and the subiculum of the hippocampus [44], both of which are critical nodes in the default mode network shown to be altered in PTSD $[1,45]$. The CAB connects the hippocampus and other regions of the medial temporal lobe with the posterior cingulate [43], an area that has been shown to exhibit alterations of gray matter integrity (thinning) in this group of participants [30]. Of similar relevance, we 
Table 1. Partial correlation of fractional anisotropy with PTSD severity: cingulum and uncinate tracts

\begin{tabular}{|c|c|c|c|c|c|c|c|c|c|}
\hline \multirow[t]{2}{*}{ Tract/FA } & \multicolumn{3}{|c|}{$\begin{array}{l}\text { CAPS score } \\
\text { (full group) }\end{array}$} & \multicolumn{3}{|c|}{$\begin{array}{l}\text { CAPS score } \\
\text { (PTSD only) }\end{array}$} & \multicolumn{3}{|c|}{$\begin{array}{l}\text { CAPS score } \\
\text { (combat controls) }\end{array}$} \\
\hline & $r$ & $p$ & $d f$ & $r$ & $p$ & $d f$ & $r$ & $p$ & $d f$ \\
\hline CAB (LH) & 0.433 & $0.001^{*}$ & 57 & 0.534 & $0.005^{*}$ & 24 & 0.141 & 0.492 & 24 \\
\hline $\mathrm{CAB}(\mathrm{RH})$ & -0.050 & 0.709 & 57 & 0.031 & 0.882 & 24 & -0.067 & 0.744 & 24 \\
\hline CCG (LH) & -0.037 & 0.780 & 57 & -0.190 & 0.352 & 24 & -0.324 & 0.106 & 24 \\
\hline CCG (RH) & -0.061 & 0.648 & 57 & -0.073 & 0.725 & 24 & -0.194 & 0.343 & 24 \\
\hline UNC (LH) & 0.002 & 0.986 & 57 & -0.072 & 0.727 & 24 & -0.048 & 0.817 & 24 \\
\hline UNC (RH) & -0.036 & 0.787 & 57 & -0.287 & 0.155 & 24 & -0.025 & 0.905 & 24 \\
\hline
\end{tabular}

* Indicates significance if $p \leq 0.008$.

Bonferroni method was used to adjust alpha threshold for multiple comparison $(0.05 / 6=0.008)$.

FA, fractional anisotropy; LH, left hemisphere; RH, right hemisphere; CAPS, Clinician Administered PTSD Scale for DSM-IV; r, partial correlation controlling for age; sex, head motion, and antidepressant use; CAB, cingulum angular bundle; CCG, cingulum cingulate gyrus endings; UNC, uncinate fasciculus.

Table 2. Partial correlation of PTSD severity with fractional anisotropy in other probabilistic white matter tracts

\begin{tabular}{|c|c|c|c|c|c|c|c|c|c|}
\hline \multirow[t]{2}{*}{ Tract } & \multicolumn{3}{|c|}{$\begin{array}{l}\text { CAPS score } \\
\mathrm{x} \text { LH FA }\end{array}$} & \multicolumn{3}{|c|}{$\begin{array}{l}\text { CAPS score } \\
\text { x RH FA }\end{array}$} & \multicolumn{3}{|c|}{$\begin{array}{l}\text { CAPS score } \\
\text { x Bilateral FA }\end{array}$} \\
\hline & $r$ & $p$ & $d f$ & $r$ & $p$ & $d f$ & $r$ & $p$ & $d f$ \\
\hline fmajor & - & - & - & - & - & - & -0.077 & 0.563 & 57 \\
\hline fminor & - & - & - & - & - & - & 0.098 & 0.461 & 57 \\
\hline ATR & -0.037 & 0.778 & 57 & -0.193 & 0.143 & 57 & - & - & - \\
\hline CST & 0.047 & 0.722 & 57 & 0.061 & 0.646 & 57 & - & - & - \\
\hline ILF & 0.097 & 0.465 & 57 & 0.001 & 0.996 & 57 & - & - & - \\
\hline SLFP & 0.091 & 0.492 & 57 & -0.028 & 0.834 & 57 & - & - & - \\
\hline SLFT & -0.092 & 0.490 & 57 & 0.075 & 0.571 & 57 & - & - & - \\
\hline
\end{tabular}

FA, fractional anisotropy; LH, left hemisphere; RH, right hemisphere; CAPS, Clinician Administered PTSD Scale for DSM-IV; r, partial correlation controlling for age; sex, head motion, and antidepressant use; fmajor, corpus callosum forceps major; fminor, corpus callosum forceps minor; ATR, anterior thalamic radiations; CST, corticospinal tract; ILF, inferior longitudinal fasciculus; SLFP, superior longitudinal fasciculus parietal endings; SLFT, superior longitudinal fasciculus temporal endings. Bonferroni method was used to adjust alpha threshold for multiple comparison $(0.05 / 12=0.004)$. No results were significant, before or after correction.

have previously reported various associations between PTSD symptom severity and the anterior hippocampus, including differences in morphometry [29], lower volume of the hippocampus-amygdala transition area [31], and both structural and anatomical dysconnectivity [32]. Given the purported associations with key regions of emotion, memory, and cognition, it is interesting to consider the implications of altered CAB integrity in the context of our earlier work with this cohort. While further study would be necessary to draw conclusions about a relationship between the current and past findings, the cumulative evidence from this cohort may pro- vide further insight into the widespread neural alterations observed in PTSD and other stress-based disorders, and highlight the importance of continued study of the role of the cingulum in the pathophysiology of PTSD.

Surprisingly, we did not replicate prior results using region-based FA. It is possible that the failure to replicate past results is due to the nature of this cross-sectional study, which was optimized for a dimensional analysis of PTSD severity versus differences between diagnostic groups. Of note, Olson et al. [46] also failed to identify dimensional differences using TRACULA. Our control 
Table 3. Partial correlation of PTSD severity with fractional anisotropy in 24 DTI ROI

\begin{tabular}{|c|c|c|c|c|c|c|c|c|c|}
\hline \multirow[t]{2}{*}{ ROI } & \multicolumn{3}{|c|}{$\begin{array}{l}\text { CAPS score } \\
\text { x LH FA }\end{array}$} & \multicolumn{3}{|c|}{$\begin{array}{l}\text { CAPS score } \\
\text { x RH FA }\end{array}$} & \multicolumn{3}{|c|}{$\begin{array}{l}\text { CAPS score } \\
\text { x single/bilateral FA }\end{array}$} \\
\hline & $r$ & $p$ & $d f$ & $r$ & $p$ & $d f$ & $r$ & $p$ & $d f$ \\
\hline CR & -0.052 & 0.692 & 58 & -0.124 & 0.344 & 58 & -0.093 & 0.481 & 58 \\
\hline ACR & -0.087 & 0.510 & 58 & -0.162 & 0.218 & 58 & -0.132 & 0.313 & 58 \\
\hline PCR & 0.033 & 0.802 & 58 & 0.006 & 0.961 & 58 & 0.020 & 0.878 & 58 \\
\hline SCR & -0.032 & 0.811 & 58 & -0.090 & 0.495 & 58 & -0.064 & 0.628 & 58 \\
\hline IC & 0.002 & 0.991 & 58 & -0.030 & 0.821 & 58 & -0.015 & 0.909 & 58 \\
\hline ALIC & -0.119 & 0.363 & 58 & -0.085 & 0.518 & 58 & -0.108 & 0.413 & 58 \\
\hline PLIC & 0.051 & 0.697 & 58 & 0.047 & 0.723 & 58 & 0.051 & 0.701 & 58 \\
\hline RLIC & 0.052 & 0.691 & 58 & -0.049 & 0.710 & 58 & -0.005 & 0.967 & 58 \\
\hline $\mathrm{EC}$ & -0.011 & 0.932 & 58 & 0.092 & 0.485 & 58 & 0.042 & 0.749 & 58 \\
\hline CC & - & - & - & - & - & - & -0.159 & 0.224 & 58 \\
\hline BCC & - & - & - & - & - & - & -0.166 & 0.206 & 58 \\
\hline GCC & - & - & - & - & - & - & 0.041 & 0.756 & 58 \\
\hline SCC & - & - & - & - & - & - & -0.232 & 0.074 & 58 \\
\hline CGC & -0.044 & 0.740 & 58 & -0.042 & 0.750 & 58 & -0.045 & 0.730 & 58 \\
\hline $\mathrm{CGH}$ & 0.055 & 0.676 & 58 & -0.057 & 0.665 & 58 & 0.001 & 0.995 & 58 \\
\hline CST & -0.266 & $0.040^{*}$ & 58 & -0.150 & 0.252 & 58 & -0.239 & 0.065 & 58 \\
\hline $\mathrm{FX}$ & - & - & - & - & - & - & -0.215 & 0.099 & 58 \\
\hline FXST & 0.086 & 0.511 & 58 & 0.054 & 0.683 & 58 & 0.080 & 0.543 & 58 \\
\hline IFO & 0.174 & 0.185 & 58 & 0.231 & 0.076 & 58 & 0.241 & 0.063 & 58 \\
\hline PTR & 0.111 & 0.397 & 58 & -0.131 & 0.320 & 58 & -0.026 & 0.845 & 58 \\
\hline SFO & -0.019 & 0.885 & 58 & 0.018 & 0.891 & 58 & 0.003 & 0.981 & 58 \\
\hline SLF & 0.186 & 0.155 & 58 & 0.109 & 0.409 & 58 & 0.157 & 0.232 & 58 \\
\hline SS & 0.031 & 0.815 & 58 & -0.046 & 0.725 & 58 & -0.011 & 0.935 & 58 \\
\hline UNC & -0.132 & 0.314 & 58 & -0.070 & 0.596 & 58 & -0.104 & 0.428 & 58 \\
\hline
\end{tabular}

\footnotetext{
$* p \leq 0.05$. No results reached significance at the level of $p \leq 0.0008$.

ROI, region of interest; FA, fractional anisotropy; LH, left hemisphere; RH, right hemisphere; CAPS, Clinician Administered PTSD Scale for DSM-IV; r, partial correlation controlling for age, sex, head motion, and antidepressant use; CR, corona radiata; PCR, posterior corona radiata; ACR, anterior corona radiata; SCR, superior corona radiata; IC, internal capsule; ALIC, anterior limb of internal capsule; PLIC, posterior limb of internal capsule; RLIC, retrolenticular part of internal capsule; EC, external capsule; CC, corpus callosum; BCC, body of corpus callosum; GCC, genu of corpus collosum; SCC, splenium of corpus callosum; CGC, supra-genual cingulate bundles; CGH, cingulum of the hippocampal region; CST, corticospinal tract; FX, fornix; FXST, fornix/stria terminalis; IFO, inferior fronto-occipital fasciculus; PTR, Posterior thalamic radiation; SFO, superior frontooccipital fasciculus; SLF, superior longitudinal fasciculus; SS, sagittal stratum; UNC, uncinate fasciculus. Bonferroni method was used to adjust alpha threshold for multiple comparison $(0.05 / 62=0.0008)$.
}

group was not fully asymptomatic, and this variance would have been lost if the data was reduced to make categorical inferences. Other reasons for the failure to replicate may be related to FA changes over the course of the illness. There is mounting evidence of increased FA early in the course of illness $[9,12,17,47]$, and reduced FA in chronic or complex PTSD (often featuring comorbid depression, brain injury, or alcohol use disorder) $[10,11,15,16,19,48]$. Homogenous samples with early onset or highly chronic cohorts might be more successful at demonstrating a relationship between PTSD and FA.

White Matter Diffusivity Alterations in PTSD

\section{Conclusion}

Our findings provide important information regarding the potential importance of the CAB in PTSD. The study also underscores the lack of consistency in diffusivity alterations in PTSD. Investigations addressing some of the current study's limitations, in particular enrolling early course vs. chronic PTSD populations, will be valuable to further advance our understanding of alterations in white matter tracts in PTSD. Specifically, such study may elucidate the role the $\mathrm{CAB}$, which has been implicated in both higher-order cognitive function and emo- 
tion processing. It will also be valuable to examine the potential role of alterations in the $\mathrm{CAB}$ relative to cognitive impairment in PTSD, perhaps especially so in older adults, as PTSD is associated with cognitive dysfunction and is a known risk factor for dementia $[49,50]$. Future studies using high-density fiber tracking, "brain bank" data, and multi-modal imaging techniques may better elucidate the relationship between both gray and white matter integrity alterations in PTSD.

\section{Acknowledgments}

This research was not conducted in a vacuum, and we would like to acknowledge some of those who have provided particular support to our work. First, and always, much gratitude is due to the Veterans who, through participation in research, have taken up yet another mantle of service for their community. We also extend our appreciation for the support we have received from the US Department of Veterans Affairs, the National Center for PTSD, the National Institute of Mental Health, the Robert E. Leet and Clara Guthrie Patterson Trust, the Brain and Behavior Foundation, and the New York Women's Committee.

\section{Statement of Ethics}

All participants provided informed consent, and all procedures undertaken were approved by the Human Studies Subcommittee (IRB) of the VA Connecticut Healthcare System.

\section{Disclosure Statement}

Dr. Chadi G. Abdallah has served as a consultant or on advisory boards for Genentech and Janssen. He also serves as editor for the journal Chronic Stress published by SAGE Publica- tions, Inc. Dr. John H. Krystal is a consultant for AbbVie, Inc., Amgen, Astellas Pharma Global Development, Inc., AstraZeneca Pharmaceuticals, Biomedisyn Corporation, Bristol-Myers Squibb, Eli Lilly and Company, Euthymics Bioscience, Inc., Neurovance, Inc., FORUM Pharmaceuticals, Janssen Research and Development, Lundbeck Research USA, Novartis Pharma AG, Otsuka America Pharmaceutical, Inc., Sage Therapeutics, Inc., Sunovion Pharmaceuticals, Inc., and Takeda Industries; is on the Scientific Advisory Board for Lohocla Research Corporation, Mnemosyne Pharmaceuticals, Inc., Naurex, Inc., and Pfizer; is a stockholder in Biohaven Medical Sciences; holds stock options in Mnemosyne Pharmaceuticals, Inc.; holds patents for Dopamine and Noradrenergic Reuptake Inhibitors in Treatment of Schizophrenia, U.S. Patent No. 5,447,948 (issued September 5, 1995), and Glutamate Modulating Agents in the Treatment of Mental Disorders, U.S. Patent No. 8,778,979 (issued July $15,2014)$; and filed a patent for Intranasal Administration of Ketamine to Treat Depression. US Application No. 14/197,767 (filed on March 5, 2014); US application or Patent Cooperation Treaty international application No. 14/306,382 (filed on June $17,2014)$. All other authors report that there are no conflicts of interest to disclose.

\section{Funding Source}

This work was supported by the US Department of Veterans Affairs (DVA) through its support of the National Center for PTSD-Clinical Neurosciences Division and through a Career Development Award (LAA); NIMH (MH-101498); Brain and Behavior Foundation Young Investigator Awards (NARSAD) (LAA, CGA); the Robert E. Leet and Clara Guthrie Patterson Trust (LAA), and a DVA Career Development Award (IK2CX000772). The content is solely the responsibility of the authors and does not necessarily represent the official views of the sponsors. The sponsors had no role in the design and conduct of the study; collection, management, analysis, and interpretation of the data; and preparation, review, or approval of the manuscript.

\section{References}

1 Akiki TJ, Averill CL, Abdallah CG: A network-based neurobiological model of PTSD: evidence from structural and functional neuroimaging studies. Curr Psychiatry Rep 2017; 19:81.

2 Pitman RK, Rasmusson AM, Koenen KC, Shin LM, Orr SP, Gilbertson MW, Milad MR, Liberzon I: Biological studies of post-traumatic stress disorder. Nat Rev Neurosci 2012; 13:769-787

3 Krystal JH, Abdallah CG, Averill LA, Kelmendi B, Harpaz-Rotem I, Sanacora G, Southwick SM, Duman RS: Synaptic loss and the pathophysiology of PTSD: implications for ketamine as a prototype novel therapeutic. Curr Psychiatry Rep 2017;19: 74.
4 O’Doherty DC, Chitty KM, Saddiqui S, Bennett MR, Lagopoulos J: A systematic review and meta-analysis of magnetic resonance imaging measurement of structural volumes in posttraumatic stress disorder. Psychiatry Res 2015;232:1-33.

5 Koch SB, van Zuiden M, Nawijn L, Frijling JL, Veltman DJ, Olff M: Aberrant resting-state brain activity in posttraumatic stress disorder: a meta-analysis and systematic review. Depress Anxiety 2016;33:592-605

6 Assaf Y, Pasternak O: Diffusion tensor imaging (DTI)-based white matter mapping in brain research: a review. J Mol Neurosci 2008; 34:51-61.

7 Hagmann P, Jonasson L, Maeder P, Thiran JP, Wedeen VJ, Meuli R: Understanding diffu- sion MR imaging techniques: from scalar diffusion-weighted imaging to diffusion tensor imaging and beyond. Radiographics 2006; 26(suppl 1):S205-S223.

8 Jellison BJ, Field AS, Medow J, Lazar M, Salamat MS, Alexander AL: Diffusion tensor imaging of cerebral white matter: a pictorial review of physics, fiber tract anatomy, and tumor imaging patterns. AJNR Am J Neuroradiol 2004;25:356-369.

9 Abe O, Yamasue H, Kasai K, Yamada H, Aoki S, Iwanami A, Ohtani T, Masutani Y, Kato N, Ohtomo K: Voxel-based diffusion tensor analysis reveals aberrant anterior cingulum integrity in posttraumatic stress disorder due to terrorism. Psychiatry Res 2006;146:231242. 
10 Sanjuan PM, Thoma R, Claus ED, Mays N, Caprihan A: Reduced white matter integrity in the cingulum and anterior corona radiata in posttraumatic stress disorder in male combat veterans: a diffusion tensor imaging study. Psychiatry Res 2013;214:260-268.

11 Isaac L, Main KL, Soman S, Gotlib IH, Furst AJ, Kinoshita LM, Fairchild JK, Yesavage JA, Ashford JW, Bayley PJ, Adamson MM: The impact of depression on Veterans with PTSD and traumatic brain injury: a diffusion tensor imaging study. Biol Psychol 2015;105: 20-28.

12 Bierer LM, Ivanov I, Carpenter DM, Wong EW, Golier JA, Tang CY, Yehuda R: White matter abnormalities in Gulf War veterans with posttraumatic stress disorder: a pilot study. Psychoneuroendocrinology 2015;51: 567-576.

13 Koch SBJ, van Zuiden M, Nawijn L, Frijling JL, Veltman DJ, Olff M: Decreased uncinate fasciculus tract integrity in male and female patients with PTSD: a diffusion tensor imaging study. J Psychiatry Neurosci 2017;42:331342.

14 Davenport ND, Lim KO, Sponheim SR: White matter abnormalities associated with military PTSD in the context of blast TBI. Hum Brain Mapp 2015;36:1053-1064.

15 Fani N, King TZ, Jovanovic T, Glover EM, Bradley B, Choi K, Ely T, Gutman DA, Ressler $\mathrm{KJ}$ : White matter integrity in highly traumatized adults with and without post-traumatic stress disorder. Neuropsychopharmacology 2012;37:2740-2746.

16 Kim SJ, Jeong DU, Sim ME, Bae SC, Chung A, Kim MJ, Chang KH, Ryu J, Renshaw PF, Lyoo IK: Asymmetrically altered integrity of cingulum bundle in posttraumatic stress disorder. Neuropsychobiology 2006;54:120-125.

17 Sekiguchi A, Sugiura M, Taki Y, Kotozaki Y, Nouchi R, Takeuchi H, Araki T, Hanawa S, Nakagawa S, Miyauchi CM, Sakuma A, Kawashima R: White matter microstructural changes as vulnerability factors and acquired signs of post-earthquake distress. PLoS One 2014;9:e83967.

18 Costanzo ME, Jovanovic T, Pham D, Leaman S, Highland KB, Norrholm SD, Roy MJ: White matter microstructure of the uncinate fasciculus is associated with subthreshold posttraumatic stress disorder symptoms and fear potentiated startle during early extinction in recently deployed service members. Neurosci Lett 2016;618:66-71.

19 Admon R, Leykin D, Lubin G, Engert V, Andrews J, Pruessner J, Hendler T: Stress-induced reduction in hippocampal volume and connectivity with the ventromedial prefrontal cortex are related to maladaptive responses to stressful military service. Hum Brain Mapp 2013;34:2808-2816.

20 Daniels JK, Lamke JP, Gaebler M, Walter H, Scheel M: White matter integrity and its relationship to PTSD and childhood trauma - a systematic review and meta-analysis. Depress Anxiety 2013;30:207-216.
21 Yendiki A, Panneck P, Srinivasan P, Stevens A, Zollei L, Augustinack J, Wang R, Salat D, Ehrlich S, Behrens T, Jbabdi S, Gollub R, Fischl B: Automated probabilistic reconstruction of white-matter pathways in health and disease using an atlas of the underlying anatomy. Front Neuroinform 2011;5:23.

22 Catani M, Thiebaut de Schotten M: A diffusion tensor imaging tractography atlas for virtual in vivo dissections. Cortex 2008;44:11051132.

23 Averill LA, Abdallah CG, Pietrzak RH, Averill CL, Southwick SM, Krystal JH, HarpazRotem I: Combat exposure severity is associated with reduced cortical thickness in combat veterans: a preliminary report. Chronic Stress (Thousand Oaks) 2017;1.

24 Butler O, Adolf J, Gleich T, Willmund G, Zimmermann P, Lindenberger U, Gallinat J, Kuhn S: Military deployment correlates with smaller prefrontal gray matter volume and psychological symptoms in a subclinical population. Transl Psychiatry 2017;7:e1031.

25 Davis MT, Holmes SE, Pietrzak RH, Esterlis I: Neurobiology of chronic stress-related psychiatric disorders: evidence from molecular imaging studies. Chronic Stress 2017;1: 2470547017710916.

26 Logue MW, van Rooij SJH, Dennis EL, Davis SL, Hayes JP, Stevens JS, Densmore M, Haswell CC, Ipser J, Koch SB, Korgaonkar M, Lebois LAM, Peverill M, Baker JT, Boedhoe PSW, Frijling JL, Gruber SA, Harpaz-Rotem I, Jahanshad N, Koopowitz S, Levy I, Nawijn L, O'Connor L, Olff M, Salat DH, Sheridan MA, Spielberg JM, van Zuiden M, Winternitz SR, Wolff JD, Wolf EJ, Wang X, Wrocklage K, Abdallah CG, Bryant RA, Geuze E, Jovanovic T, Kaufman ML, King AP, Krystal JH, Lagopoulos J, Lanius R, Liberzon I, McGlinchey RE, McLaughlin KA, Milberg WP, Miller MW, Ressler KJ, Veltman DJ, Stein DJ, Thomaes K, Thompson PM, Morey RA: Smaller hippocampal volume in posttraumatic stress disorder: a multisite ENIGMA-PGC study: subcortical volumetry results from posttraumatic stress disorder consortia. Biol Psychiatry 2017;83:244-253.

27 Liberzon I, Martis B: Neuroimaging studies of emotional responses in PTSD. Ann N Y Acad Sci 2006;1071:87-109.

28 LeDoux JE: Emotion circuits in the brain. Annu Rev Neurosci 2000;23:155-184.

29 Akiki TJ, Averill CL, Wrocklage KM, Schweinsburg B, Scott JC, Martini B, Averill LA, Southwick SM, Krystal JH, Abdallah CG: The association of PTSD symptom severity with localized hippocampus and amygdala abnormalities. Chronic Stress (Thousand Oaks) 2017;1:2470547017724069.

30 Wrocklage KM, Averill LA, Cobb Scott J, Averill CL, Schweinsburg B, Trejo M, Roy A, Weisser V, Kelly C, Martini B, Harpaz-Rotem I, SouthwickSM, Krystal JH, Abdallah CG: Cortical thickness reduction in combat exposed U.S. veterans with and without PTSD. Eur Neuropsychopharmacol 2017;27:515-525.
31 Averill CL, Satodiya RM, Scott JC, Wrocklage KM, Schweinsburg B, Averill LA, Akiki TJ, Amoroso T, Southwick SM, Krystal JH, Abdallah CG: Posttraumatic stress disorder and depression symptom severities are differentially associated with hippocampal subfield volume loss in combat veterans. Chronic Stress (Thousand Oaks) 2017;1.

32 Abdallah CG, Wrocklage KM, Averill CL, Akiki T, Schweinsburg B, Roy A, Martini B, Southwick SM, Krystal JH, Scott JC: Anterior hippocampal dysconnectivity in posttraumatic stress disorder: a dimensional and multimodal approach. Transl Psychiatry 2017;7:e1045.

33 Blake DD, Weathers FW, Nagy LM, Kaloupek DG, Gusman FD, Charney DS, Keane TM: The development of a clinician-administered PTSD scale. J Trauma Stress 1995;8:75-90.

34 First MB, Spitzer RL, Gibbon M, Williams JBW: Structured Clinical Interview for the DSM-IV-TR Axis I Disorders, Research Version, Patient Edition. New York, Biometrics Research, New York State Psychiatric Institute, 2002.

35 Keane TM, Fairbank JA, Caddell JM, Zimering RT, Taylor KL, Mora CA: Clinical evaluation of a measure to assess combat exposure. Psychol Assess J Consult Clin Psychol 1989;1: 53-55.

36 Holdnack HA: Weschler Test of Adult Reading: WTAR. San Antonio, Psychological Corporation, 2001.

37 Yendiki A, Koldewyn K, Kakunoori S, Kanwisher N, Fischl B: Spurious group differences due to head motion in a diffusion MRI study. Neuroimage 2014;88:79-90.

38 Behrens TE, Johansen-Berg $\mathrm{H}$, Woolrich MW, Smith SM, Wheeler-Kingshott CA, Boulby PA, Barker GJ, Sillery EL, Sheehan K, Ciccarelli O, Thompson AJ, Brady JM, Matthews PM: Non-invasive mapping of connections between human thalamus and cortex using diffusion imaging. Nat Neurosci 2003;6: 750-757.

39 Jenkinson M, Beckmann CF, Behrens TE, Woolrich MW, Smith SM: FSL. Neuroimage 2012;62:782-790.

40 Fischl B: FreeSurfer. Neuroimage 2012;62: 774-781.

41 Wisse LE, Reijmer YD, ter Telgte A, Kuijf HJ, Leemans A, Luijten PR, Koek HL, Geerlings MI, Biessels GJ; Utrecht Vascular Cognitive Impairment Study Group: Hippocampal disconnection in early Alzheimer's disease: a 7 tesla MRI study. J Alzheimers Dis 2015;45: 1247-1256.

42 Wu Y, Sun D, Wang Y, Wang Y, Ou S: Segmentation of the cingulum bundle in the human brain: a new perspective based on DSI tractography and fiber dissection study. Front Neuroanat 2016;10:84.

43 Ezzati A, Katz MJ, Lipton ML, Zimmerman ME, Lipton RB: Hippocampal volume and cingulum bundle fractional anisotropy are independently associated with verbal memory in older adults. Brain Imaging Behav 2016;10: 652-659. 
44 Heilbronner SR, Haber SN: Frontal cortical and subcortical projections provide a basis for segmenting the cingulum bundle: implications for neuroimaging and psychiatric disorders. J Neurosci 2014;34:10041-10054.

45 Sripada RK, King AP, Welsh RC, Garfinkel SN, Wang X, Sripada CS, Liberzon I: Neural dysregulation in posttraumatic stress disorder: evidence for disrupted equilibrium between salience and default mode brain networks. Psychosom Med 2012;74: 904-911.

46 Olson EA, Cui J, Fukunaga R, Nickerson LD, Rauch SL, Rosso IM: Disruption of white mat- ter structural integrity and connectivity in posttraumatic stress disorder: a TBSS and tractography study. Depress Anxiety 2017;34: 437-445.

47 Zhang L, Zhang Y, Li L, Li Z, Li W, Ma N, Hou C, Zhang Z, Zhang Z, Wang L, Duan L, Lu G: Different white matter abnormalities between the first-episode, treatment-naive patients with posttraumatic stress disorder and generalized anxiety disorder without comorbid conditions. J Affect Disord 2011;133:294299.

48 Schuff N, Zhang Y, Zhan W, Lenoci M, Ching C, Boreta L, Mueller SG, Wang
Z, Marmar CR, Weiner MW, Neylan TC: Patterns of altered cortical perfusion and diminished subcortical integrity in posttraumatic stress disorder: an MRI study. Neuroimage 2011;54(suppl 1):S62S68.

49 Greenberg MS, Tanev K, Marin MF, Pitman RK: Stress, PTSD, and dementia. Alzheimers Dement 2014;10:S155-S165.

50 Yaffe K, Vittinghoff E, Lindquist K, Barnes D, Covinsky KE, Neylan T, Kluse M, Marmar C: Posttraumatic stress disorder and risk of dementia among US veterans. Arch Gen Psychiatry 2010;67:608-613. 